\title{
Research on Evaluation of University S\&T Innovation Efficiency in Liaoning Province
}

\author{
Shihong Wei \\ School of Economics and Management \\ Dalian University \\ Dalian, China
}

\author{
Kaiming Tan \\ School of Economics and Management \\ Dalian University \\ Dalian, China
}

\begin{abstract}
Based on the evaluation index system of S\&T innovation efficiency of university, a comprehensive evaluation on S\&T innovation efficiency of university in Liaoning province and the other coastal areas is made by using DEA method, and the constraint variable and inhibiting bottleneck of the innovation efficiency of university in Liaoning province is analyzed according to the evaluation result. Therefore, several suggestions are proposed by its use of reference to promote the S\&T innovation efficiency of university in Liaoning province.
\end{abstract}

Keywords-S\&T innovation efficiency; Liaoning province; university; DEA method

\section{INTRODUCTION}

In 2006, the Party Central Committee and the State Council put forward the independent innovation strategy and stated clearly to build China into an innovative country by 2020. Universities, as an important part of the state innovation system, play a significant role in basic research and original innovation. As an old industrial base, Liaoning is also a province with 94 universities located. These universities are an important part in building an innovationoriented Liaoning and bear significant responsibilities to improve the independent innovation capability of Liaoning. Therefore, evaluating the university S\&T innovation efficiency in Liaoning and analyzing its advantages and disadvantages are of great importance in the formulation of science and technology resource allocation policy. ${ }^{[1]}$

At present, empirical studies related to university S\&T innovation mainly focus on innovation capacity evaluation and innovation efficiency evaluation. Many research achievements are made in innovation capacity evaluation, while a relatively small volume is made in innovation efficiency evaluation. Zhou Jing et al made researches on different university systems and scale efficiencies in accordance with the data (1994-2002) of national universities and colleges ${ }^{[2]}$. Zhang Haiyan et al made a clustering analysis on university S\&T innovation activities nationwide from 2002 to 2005 by using SPSS13.0. They also conducted comparative researches on the appropriation expenditure and personnel investment efficiency during innovation activities between different universities in the four years. As a result, they found DEA in 24 areas effective, while for other 6 areas, the non-DEA was effective. Meanwhile, they suggested strengthening input intensity and supervision effort of scitech appropriation in non-DEA areas ${ }^{[3]}$. Selecting colleges and universities in China's 31 provinces as decision-making units, $\mathrm{Xu}$ Juan made researches on relatively effective evaluation of technical efficiency, pure technical efficiency and scale efficiency and pointed out that there was no necessary connection between the relative efficiency of the scientific research in universities and the regional economy. She also pointed out that the development of scientific research in colleges and universities lied in high efficiency which brought more outputs of scientific research ${ }^{[4]}$. By studying input and output efficiencies of scientific research in universities of China's 29 provinces through DEA, Sun Shimin et al learned about the input and output efficiency of scientific research in different universities and found out the input shortfall and output redundancy of non-DEA efficiency in different areas. In accordance with the above results, they found out that input and output efficiencies of scientific research in universities of western area were relatively low and most of them were on a stage with increasing scale efficiency. Therefore, central and regional governments related to scientific research at colleges and universities should make no efforts to increase investment on scientific research resource to universities in western area and improve the output of large scientific research investment ${ }^{[5]}$.

Liaoning is a large educational province and universities play a very important role in S\&T innovation system. Based on this, this paper chooses the S\&T innovation efficiency of Liaoning's universities as the object and takes 10 coastal provinces and cities which have advanced economy and technology as samples to conduct data envelopment analysis on S\&T innovation efficiency. Based on this, comparative analysis is made in this paper between the S\&T innovation efficiency of Liaoning's universities and other samples, thus providing theoretical guidance and policy basis for relevant governments in Liaoning to their formulation of science and technology policy and the reform and development of higher education.

\section{DATA AND METHOD}

\section{A. Research Method}

From the previous analysis of S\&T innovation efficiency, the DEA method is mostly used by the domestic scholars. 
The DEA method is very suitable for the university with multi input and multi output, and DEA method can also ignore the research object in the middle of the production process. Therefore, this paper also takes the DEA method to evaluate.

DEA method was proposed by A. Charnes and W.W.Cooper in 1978, which is used to evaluate the relative validity ${ }^{[6]}$. The method assumes that there are $n$ variables:

$$
T=\left\{(X, Y) \mid \sum_{j=1}^{n} X_{j} \lambda_{j} \leq X, \sum_{j=1}^{n} Y_{j} \lambda_{j} \geq Y, \lambda_{j} \geq 0, j=1,2, \ldots, n\right\}
$$

DEA method is as follows :

$$
\begin{aligned}
& \min \left[\theta-\varepsilon\left(\sum_{i=1}^{m} S_{i}^{-}+\sum_{r=1}^{s} S_{r}^{-}\right)\right] \\
& \text {s.t. } \\
& \sum_{j=1}^{n} x_{i j} \lambda_{j}+S_{i}^{-}=\theta x_{i j 0}, i \in(1,2, \ldots, m) \\
& \sum_{j=1}^{n} y_{r j} \lambda_{j}-S_{i}^{+}=y_{r j 0}, r \in(1,2, \ldots, s) \\
& \theta, \lambda_{j}, S_{i}^{-}, S_{r}^{+} \geq 0, j=1,2, \ldots, n
\end{aligned}
$$

According to formula (1), $S_{r}^{+} 、 S_{i}^{-}$are slack variables, $\varepsilon$ is non-archimedes infinitesimal, $\theta$ is the projection of DMU. When $\theta^{0}=1, S^{-0}=0, S^{-0}=0$, DMU means DEA effective, when $\theta^{0}=1, S^{-0} \neq 0, S^{-0} \neq 0$, DMU is weak DEA efficient; $\theta^{0}<1, S^{-0} \neq 0, S^{-0} \neq 0$, DMU is non-DEA Effectiv. If there exists $\lambda_{j}$ such that $\sum_{j=1}^{n} \lambda_{j}=1$, DMU is a fixed Scale Benefit; if $\frac{1}{\theta} \sum_{j=1}^{n} \lambda_{j}<1$, DMU is an increased Scale Benefit, if $\frac{1}{\theta} \sum_{j=1}^{n} \lambda_{j}>1$, DMU is a decreased scale benefit ${ }^{[7]}$.

\section{B. Setting Measures and Data Sources}

1) Input index and output index: Capital and workforce inputs are major indexes to evaluate input and output efficiencies and are also used in this paper. However, as for university S\&T innovation efficiency, capital and workforce inputs refer to $\mathrm{R} \& \mathrm{D}$ appropriation expenditure and personnel investment, which are common indexes used by scholars. Appropriation expenditure means spending used in basic research, applied research and experimental development, while personnel investment refers to university staff involved in project research, management and ancillary work of basic research, applied research and experimental development. Sci-Tech funds and technological staff can be used to characterize the Sci-Tech innovation scales and potentials and they also embody the input capability of university S\&T innovation.
Referring to output index, papers and patents are the indexes often used by scholars and are also used in this paper. In addition, in order to highlight the original technology innovation, the paper selects scientific papers and patents as output measurement indexes. It should be pointed out that this paper regards patent application quantity rather than patent authorization quantity as patent innovation quality, because patent authorization quantity needs time for approval. If patent authorization quantity is regarded as the measurement index, there will be information distortion to a certain degree. Meanwhile, information about patent authorization quantity is almost contained in patent application quantity[8]. Scientific papers include both international papers and domestic papers. The former one refers to those papers published by Chinese scientific and technical personnel and collected by SCI. The latter one refers to those essays collected in Chinese Scientific and Technical Papers Citation Database (CSTPCD).

2) Data sources: Due to the periodicity of science and technology innovation activities, there must be a delay between input and output. Hence, time difference should be considered. Generally speaking, scholars believe that the technological innovation input-to-output delay is 2 years. Consequently, this paper, as most scholars do, sets the delay time as 2 years. This paper chooses the input data of 2013

\begin{tabular}{|c|c|c|c|c|}
\hline & \multicolumn{2}{|c|}{ Input (2013) } & \multicolumn{2}{|c|}{ Output (2015) } \\
\hline & $\begin{array}{c}\text { R\&D Funds } \\
\text { (100 million } \\
\text { yuan })\end{array}$ & $\begin{array}{c}R \& D \\
\text { Personnel } \\
(10000 \\
\text { persons })\end{array}$ & $\begin{array}{c}\text { Scientific } \\
\text { Paper } \\
\text { (unit) }\end{array}$ & $\begin{array}{c}\text { Innovat } \\
\text { ion } \\
\text { Patent } \\
\text { Applied } \\
\text { (item) }\end{array}$ \\
\hline Beijing & 136.65 & 51.03 & 34855 & 38050 \\
\hline Tianjin & 50.82 & 22.67 & 11024 & 6223 \\
\hline Hebei & 10.20 & 3.16 & 5039 & 2026 \\
\hline Liaoning & 41.36 & 8.01 & 11900 & 6943 \\
\hline Shanghai & 71.50 & 24.53 & 32095 & 15445 \\
\hline Jiangsu & 80.74 & 7.09 & 35059 & 25682 \\
\hline Zhejiang & 47.28 & 7.75 & 13945 & 16624 \\
\hline Shandong & 33.42 & 3.67 & 16497 & 8256 \\
\hline Fujian & 11.09 & 4.80 & 6064 & 4529 \\
\hline Guangdong & 45.83 & 5.61 & 18400 & 9759 \\
\hline
\end{tabular}
and output data of 2015. All these data come from China Statistical Yearbook on Science and Technology of 2013 and 2015 as shown in "Table I".

TABLE I. DATA COMING FROM CHINA STATISTICAL YEARBOOK ON SCIENCE AND TECHNOLOGY OF 2013 AND 2015

\section{RESULT AND ANALYSIS}

\section{A. Result}

By DEA method, S\&T innovation efficiency of university is shown in "Table II". 


\section{CONCLUSION}

TABLE II. EFFICIENCY VALUE OF UNIVERSITY S\&T INNOVATION

\begin{tabular}{lllllll}
\hline & $\theta$ & $\frac{1}{\theta} \sum \lambda_{j}$ & $S_{1}^{-}$ & $S_{2}^{-}$ & $S_{1}^{+}$ & \multicolumn{1}{c}{$S_{2}^{+}$} \\
\hline Beijing & 1 & 1 & 0 & 0 & 0 & 0 \\
\hline Tianjin & 0.773 & 0.423 & 0 & 0 & 0 & 260.08 \\
\hline Hebei & 0.537 & 1.326 & 0 & 67.99 & 0 & 122.72 \\
\hline Liaoning & $\mathbf{0 . 4 7 9}$ & $\mathbf{1 . 0 0 6}$ & $\mathbf{0}$ & $\mathbf{1 8 4 7 . 6}$ & $\mathbf{2 . 6 1}$ & $\mathbf{0}$ \\
\hline Shanghai & 0.943 & 0.958 & 6.22 & 0 & 0 & 626.56 \\
\hline Jiangsu & 1 & 1 & 0 & 0 & 0 & 0 \\
\hline Zhejiang & 1 & 1 & 0 & 0 & 0 & 0 \\
\hline Shandong & 0.829 & 2.338 & 0 & 0 & 0 & 74.45 \\
\hline Fujian & 1 & 1 & 0 & 0 & 0 & 0 \\
\hline Guangdong & 0.635 & 1.529 & 0 & 0 & 0 & 72.27 \\
\hline
\end{tabular}

B. Results Analysis

1) Efficiency analysis: Efficiency value $(\theta)$ of university S\&T innovation in Liaoning is only 0.479 , ranking in the last place in all evaluated provinces and cities. This shows that efficiency value of university S\&T innovation in Liaoning is lagged behind among eastern coastal areas. Although universities in Liaoning rank the fifth in eastern coastal areas as for its S\&T resources, their S\&T innovation efficiency is at a low level. A main reason is that the construction of scientific and technical management mechanism in Liaoning's universities is relatively backward and its resources have not been used fully. Hence, universities in Liaoning should strengthen scientific and technical management mechanism reform, deepen scientific and technical management mechanism construction, make full use of research and talent advantages and improve S\&T innovation efficiency.

2) Slack variable analysis: "Table II" shows that the slack variable of R\&D personnel in Liaoning's universities is not zero, which indicates that there is a large redundancy and also shows that the personnel input has not played a full role in scientific and technological output. Hence, universities in Liaoning should strengthen its talent incentive system to release their innovation abilities. The slack variable of scientific papers in Liaoning's universities is not zero, which shows that this factor has not reached an effective level. It declares that universities in Liaoning have not attached enough attention to basic researches, which deserves their notice.

3) Scale benefit analysis: From "Table II", it can be seen that ${ }^{\frac{1}{\theta} \sum \lambda_{j}}$ in Liaoning is 1.006 . It is at a stage of decreasing returns, which shows that scientific and technological innovation activities in Liaoning are in diseconomies of scale, indicating that the increment of innovation output is less than the input. It shows that overlapping investment and waste are serious and innovation resources have not been used sufficiently [3]. Therefore, in addition to increasing innovation input steadily, universities in Liaoning need to optimize the input structure of S\&T innovation to allocate innovation resources rationally and improve S\&T innovation efficiency.

\section{A. Conclusion}

This paper, using the method of DEA, makes a comprehensive evaluation on S\&T innovation efficiency for universities in 10 coastal provinces and cities. Based on this research, the paper analyzes university S\&T innovation efficiency of Liaoning province. The result shows that the S\&T innovation efficiency value of Liaoning is 0.479 , ranking the last among all the evaluated provinces and cities. At the same time, its human resource is redundant, problems exist in science papers and the scale return of its S\&T innovation activities is at a decreasing stage. All these show that S\&T innovation activities in Liaoning province are at a diseconomy scale stage, overlapping investment and waste are serious with a low technology transfer rate.

\section{B. Suggestions}

1) Strengthen the reform intensify of $S \& T$ management system: The aim of S\&T management system reform is to create a favorable innovation environment which means the resources supply efficiency of S\&T management department. It can make sure that all resources can be used effectively [9]. The achievement of the aim needs reform in the following three levels. Firstly, it is concerned with the university system. Universities should break course barriers to make academic exchange and cooperation and share academic resources. At the same time, universities need to formulate policies to support innovation. Secondly, at a strategic level, the university development should be closely combined with the national and regional development. Effective supply should be provided, such as the establishment of university science park and the development of market oriented technological achievements. Thirdly, at the cultural level, we should establish a campus culture to encourage innovation, foster adventurous spirit, accept failures and build confidence among innovation teams and talents.

2) Mobilize the initiative of $S \& T$ innovation personnel in Liaoning: Scientific and technological talents in universities are the basic element to guarantee Liaoning to become an innovative province. Therefore, when implementing strategy of talent strong province, increasing education inputs and improving talent quality, the government needs to develop an open, flow and competitive talent use mechanism to encourage innovation, mobilize factors, such as technology, management and knowledge, to participate in distribution and increase incentive measures to raise talents enthusiasm and creativity. Firstly, universities should put innovative team cultivation as their priority and foster scientific and technical innovation groups with selfinnovation ability to solve major scientific and technical problems for the national and regional economic and social development, cultivate a group of excellent top-notch personnel and academic leader and train outstanding academic teams. All these talents play a decisive role in 
improving university S\&T innovation. Secondly, universities should strengthen the cultivation of teachers' scientific research ability and improve talent management system. As a significant force in scientific research in university, university teachers should improve their scientific research ability, which is both the requirement of improving students' ability and self-development. University teachers should improve their scientific research ability through undertaking research projects, participating in academic conferences and other methods. At the same time, universities need to improve and perfect the incentive mechanism to upgrade the talent management ability.

3) Optimize S\&T innovation input structure: Firstly, in order to improve the efficiency of S\&T input, we should establish a set of scientific and effective performance evaluation system to evaluate S\&T input performance correctly, strengthen evaluation system on achievement transformation, and set corresponding evaluation index to make sure whether the scientific and technological achievements has transferred into productive forces and met the market demands. Secondly, universities should make a rational allocation of inputs between the application development research and basic research, build multilateral scientific and technological cooperation mechanism according to the basic principle of complementary advantages and benefit-sharing, encourage teachers in universities, especially research-oriented universities, to work on basic research, strive to create an atmosphere for technological innovation and knowledge innovation and build a university S\&T innovation system with basic research as the core. Finally, universities should constantly improve the science and technology capital allocation policy, establish a reasonable and effective "input-output" mechanism and actively explore a management system suitable for scientific and technological resources of modern universities so as to combine scientific achievement and scientific \& technology input effectively, optimize scientific and technological resources and achieve a high input efficiency.

\section{ACKNOWLEDGMENT}

This work was supported by Liaoning Provincial Social Sciences Foundation 2013 (No. L13BJY030) and Economic and Social Development Foundation of Liaoning Province (No. 2016lslktglx-02).

\section{REFERENCES}

[1] Li Ying, Cui Yuwei. Evaluation Research on S\&T Innovation Efficiency of Local Universities [J]. Journal of Northeast Normal University (Philosophy and Social Science Edition) 2011, (2):177181

[2] Zhou Jing. Research on System Efficiency and Scale Efficiency of S\&T Innovation in Different Regions [J]. R\&D Management, 2005, (17): $110-117$
[3] Zhang Haiyan. Comparative Study of S\&T Innovation Efficiency between Different Areas from 2002 to 2005 [J]. Science \& Technology Progress and Policy, 2007, 24(11): 109-114.

[4] Xu Juan. Research on Relative Efficiency Evaluation of Innovation Input in Various Universities [J]. Tsinghua Journal of Education 2009 30(2): 76-80.

[5] Sun Shimin, Xiang Hualu, Rambo. Analysis of University Innovation Input and Output Efficiencies in Different Regions [J]. Science of Science and Management of Science \& Technology 2007, (7): 18-21.

[6] Charness, A., Cooper, W.W.,Rhodes, E. Measuring the Efficiency of Decision Units [J]. European Journal of Operational Research,2000,(2): 95.

[7] Wei Quanling. DEA Method for Relative Efficiency Evaluation [M] Beijing: China Renmin University Press, 2004.

[8] Pan Xiongfeng, Zhang Weiwei. Convergence Analysis of Chinese Regional Innovation Based on Spatial Effect [J]. Journal of Industrial Engineering and Engineering Management, 2013, (1): 61-65

[9] Zhou Helin, Wang Anyou. Characteristics of Human Resources Management and S\&T Management Innovation [J]. Scientific Management Research ,2002,(10): 53-56. 